Article

\title{
Issue Spatiality: A Conceptual Framework for the Role of Space in Public Discourses
}

\author{
Daniela Stoltenberg \\ Institute for Media and Communication Studies, Freie Universität Berlin, Germany; \\ E-Mail: daniela.stoltenberg@fu-berlin.de
}

Submitted: 22 December 2020 | Accepted: 26 March 2021 | Published: 23 July 2021

\begin{abstract}
Public spheres research has traditionally sidestepped questions of space by focusing on a priori delineated political territories, most prominently national public spheres. While this approach has always lacked nuance, it has become acutely insufficient nowadays, as digital communication technologies easily enable a host of heterogeneous actors to draw public attention to spaces and places at any scale, and communicatively connect places anywhere in the world. This conceptual article argues that communication scholars need to reconsider the spaces embedded in the content of public discourses. Drawing on the notion of issue publics, it understands the public definition of issues as inextricably linked to the places that are communicatively associated with them, causing issue spaces to emerge. The issue space is constructed through place-naming whenever public actors reference places in the context of issues. The article develops issue spatiality as an analytical framework to understand the role of place and space in public discourse. It discusses how issue spatiality enables a better understanding of the increasingly complex scales of public communication, and outlines several dimensions of issue spatiality. Drawing on communication infrastructure literature, it proposes socio-spatial inequalities of communicative resources as important predictors of issue spatiality, along with the habits of professional communicators, and local problem properties. Gazetteers and mapping techniques are introduced as methodological interventions required for the empirical use of issue spatiality.
\end{abstract}

\section{Keywords}

communication geography; issue space; issue spatiality; place-naming; public discourse; public sphere

\section{Issue}

This article is part of the issue "Spaces, Places, and Geographies of Public Spheres" edited by Annie Waldherr (University of Vienna, Austria), Ulrike Klinger (European University Viadrina, Germany) and Barbara Pfetsch (Freie Universität Berlin, Germany / Weizenbaum-Institute for the Networked Society, Germany).

(C) 2021 by the author; licensee Cogitatio (Lisbon, Portugal). This article is licensed under a Creative Commons Attribution 4.0 International License (CC BY).

\section{Introduction}

Public communication, in traditional as well as digital media, abounds with spatial cues: Newspapers report on floods in Manila, the capital of the Philippines, or television crews are sent out to cover wildfires in Australia. The municipal government of Kiel, a mediumsized German city, declares a climate emergency and publishes the decision on its website. Climate activists organize a protest in front of the town hall in Lisbon, Portugal. A private individual's Twitter post-claiming that their child, living in Northern France, has never seen snow-gets shared a thousand times.
In each of these examples, through the conjunction of a topic or event and a place, an issue becomes localized-in this case, the issue of climate change. Instead of remaining a spatially amorphous 'global' issue, through "place-naming" (Wiard \& Pereira, 2019, p. 652; see also Gutsche, 2014, p. 504), a more specific issue map emerges: A map with places of action and inaction; places which pollute and places which suffer the consequences; places where things are developing for the better, and others for the worse. Taken together, these instances of place-naming facilitate a collective understanding of the spatial dimension of issues, which in turn guides political attention and, in many cases, resources. 
Yet, the spatiality embedded in the content of public communication has received limited attention. For journalistic coverage, news geography (Gasher \& Klein, 2008; Wilke et al., 2012) and news values research (Galtung \& Ruge, 1965; Ruhrmann et al., 2003) offer some guidance. In the case of digital communication, with its larger and more heterogeneous actor set, its diversity of voices, and its organization into networked "issue publics" (Bennett et al., 2015), however, the spaces of public communication have received very little attention. While some research has investigated the locations of actors and the spatiality of networks, the spaces embedded within the content of digital public communication are especially understudied.

Part of this omission can probably be attributed to a lack of theoretical concepts to guide empirical descriptions and explanations of these spaces. This article proposes the concept of issue spatiality as a framework for describing and understanding the spaces of issue publics.

Issues are socially constructed through the public utterance of conflicting understandings of a topic (Miller \& Riechert, 2001, p. 109). Especially in digital public spheres, issues are often made public through the engagement of networks of topically focused actors, which are referred to as issue publics (Bennett et al., 2015). Such an understanding of issues as socially constructed through public communication can be brought together with the understanding of space put forward by spatial sociologists (e.g., Löw, 2008). They understand spaces as constructed through the perception of objects as relating to each other (Löw, 2008, p. 35), with communication being one crucial mechanism for creating this (collective) perception (Knoblauch \& Steets, 2020, pp. 140-141). Bringing together issues and spaces, spatiality can be understood as a communicatively constructed dimension of any issue. Issue spatiality emerges because public communication is localized and tied to places, that is, named and geographically marked sites (Löw, 2008, p. 42). This public reference to locations is what Wiard and Pereira (2019, p. 652) call "place-naming."

In Section 2, I will discuss how space is currently studied in public communication research and why a more explicit conceptual framework is necessary. Section 3 more thoroughly introduces the concept of issue spatiality and its dimensions. Also included is a discussion of the question of scale and probable predictors for issue spatiality. In Section 4, I discuss the necessary steps towards the concept's empirical application. Finally, Section 5 concludes the article, highlights connections to existing fields of public communication scholarship, and briefly lays out a research agenda.

\section{The Spaces of Public Communication}

Following Pfetsch et al. (2019), there are three ways in which space is inscribed in digital public spheres: the spatiality of actors, the spatiality of networks, and the spa- tiality of content. While space has overall not been a primary focus of public spheres research, comparatively more can be said about actor spatiality (where actors belonging to a public sphere are located) and network spatiality (how actors belonging to a public sphere form communicative networks in space).

Public spheres can be understood as intermediaries between different social systems, geared towards the public exchange of information and opinions, and their relay to the political system (Gerhards \& Neidhardt, 1991, pp. 44-45). This process of information and opinion exchange, in which public issues are collectively interpreted, is commonly referred to as public discourse. The notion of public spheres is intimately linked to Jürgen Habermas's (1992) work on the emergence of the Bourgeois public sphere, although his insistence on rational deliberation as the sole communicative mode has been challenged (e.g., Fraser, 1990). I understand public spheres as systems of meaning-making about public issues, without putting a priori limits to acceptable communicative modes or types of contributions. Traditionally, public spheres have been understood to consist of a multitude of partly connected arenas (Gerhards \& Neidhardt, 1991, p. 49; Habermas, 1996, p. 374). These arenas varied in size, including small encounter publics, larger assemblies, and the publics of mass media (Gerhards \& Neidhardt, 1991, pp. 50-55), with the larger formats being more exclusive and harder for speakers to access.

Yet, the increasing importance of digital media in general, and social media in particular, has brought into question how much these characterizations apply to new digital public spheres (e.g., Benkler, 2006; Schäfer, 2016). Entrance thresholds to public discourses have lowered, allowing for a greater heterogeneity of speakers (Waldherr, 2017, pp. 540-541) which enables actors to organize around shared issues and to strive towards their definition (Bennett et al., 2015, p. 109). This increasing organization of public spheres into 'issue publics' revitalizes the question of how issues are constructed in public discourse. Following Miller and Riechert (2001, p. 108), issues are produced in public discourses, when stakeholders with competing interests choose what frames and terms to highlight in discussing social problems. I argue that the question of 'where?' has been underappreciated in the study of this process. This is where the concept of issue spatiality can help.

Perhaps unsurprisingly, given the intimate connection of public spheres with the political system and their historical emergence in conjunction with the territoriality of nation-states in the 18th century (Fraser, 2007, p. 10; Wallner \& Adolf, 2014, pp. 87-88), public spheres theory has until recently been primarily concerned with national public spheres. Here, the territory of the nation-state, its political system, and the public sphere were seen as largely congruent. Over the past decades, the concurrent trends of digitalization and growing transnationalism of politics, commerce, and 
human mobility have de-naturalized this alignment of public spheres and nation-states. They have integrated actors into a multiplicity of spatial contexts (Lingenberg, 2014, p. 70), and sparked a new interest in the spatiality of public spheres.

Research has focused on how transnational issues engage actors from different countries, be it in global (Castells, 2008) or European public spheres (Risse, 2015). Such transnational public spheres pose some theoretical challenges, as they partially detach public discourses from territorially-bounded political communities. Yet, empirically, the emergence of transnational social challenges has undoubtedly brought together interlocutors who are not located within a single nation-state and who do not address state actors (Fraser, 2007, p. 14).

In terms of actor spatiality, actors from geographically dispersed locations now frequently form one public sphere, and new, transnational actors emerge. On the flipside, digital media enabled a rise of hyperlocal (neighborhood-level) journalism, allowing very local actors to gain publicity (Jangdal, 2021). This suggests growing flexibility in terms of actor locations and scales, with both hyperlocal and transnational actors gaining importance. At the same time, actors in digital spheres are strongly clustered in metropolitan areas (Takhteyev et al., 2012) and the resource-rich Global North (Leetaru et al., 2013), indicating a persistent inequality in access and visibility.

Public communication networks (i.e., the way actors connect with each other in their communication) are also increasingly disembedded from territories. This is visible, for instance, in the substantial audience share of digital local newspapers that are not located within the physical circulation area (Wehden \& Stoltenberg, 2019) and in the way actors form geographically dispersed micronetworks of news sources (Volkmer, 2014, p. 3). Activist issue publics, mobilizing around transnational social justice issues, frequently form ties across national boundaries (Bennett et al., 2015). Still, space continues to be a meaningful structuring principle in digital communication networks, with many ties remaining in close spatial proximity, even within the same metropolitan area (Pfetsch et al., 2019; Takhteyev et al., 2012).

In terms of actor and network spatiality, research, therefore, suggests a de-centering of fixed national territories and simultaneous trends of upscaling and downscaling of public spheres. That is not to say that digital public spheres are automatically detached from national territories. Rather, while mass-mediated public spheres were strongly bound to these territories through political, language-based, and economic constraints, digital media afford and enable more flexible spatialities of public communication. Even mass media themselves are less deterministically tied to specific territories in digital contexts (Hess, 2013; Wehden \& Stoltenberg, 2019). Yet, actors only come together in public spheres around objects of shared interest. Especially within digital media, which are less driven by the curation of journalistic institu- tions, issues are the glue holding public spheres together. This proposition is captured by the concept of online issue publics, which are "constituted by a communication and networking process in which various actors come together to define an issue and establish a configuration of actors connected to that issue" (Bennett et al., 2015, p. 111).

These issues have a spatial dimension, which is constructed when actors make relevant the question of 'where?' in public discourses. As digital public spheres are more strongly structured by issues and less aligned with (national) territories than mass-mediated public spheres, understanding the spatiality of public issues is a critical challenge. This requires a stronger theoretical framework for how public discourses shape a collective understanding of the geographical shape of social problems and more empirical inquiry into the spaces of communication about issues. Yet, scholarship in this area has been scarce, especially in relation to digital media.

Relevant contributions stem almost exclusively from journalism studies. News geography research is explicitly concerned with understanding how locations make events newsworthy and what the resulting journalistic map of the world looks like (Gasher \& Klein, 2008, p. 194). Somewhat predictably, it suggests an overemphasis on events in geopolitical power centers (Gasher \& Klein, 2008, p. 205; Wilke et al., 2012, p. 315) and a lack of coverage on sub-Saharan Africa (Wilke et al., 2012, p. 307). Beyond this, countries close to the medium's location receive more attention (Kwak \& An, 2014, p. 303; Wilke et al., 2012, p. 309), as do conflict regions (Gasher \& Klein, 2008, p. 205; Kwak \& An, 2014, p. 306; Wilke et al., 2012, p. 315).

These patterns can be explicated by news values. Going back to the seminal work of Galtung and Ruge (1965, pp. 70-71), news values research has hypothesized media coverage to be driven partly by geography. They posited three news factors with a spatial dimension: cultural proximity (similarity between the place of events and the place of coverage), relevance (a relation between the two places), and reference to elite nations. Proximity has since been described in more detail, with more recent research differentiating between spatial, political, economic, and cultural proximity (Ruhrmann et al., 2003, pp. 54-55).

While most research in this area is concerned with international news events, there is also a small body of work focused on local news coverage. In many ways, these studies reproduce findings from news geography research at a smaller scale. In particular, in urban local news, places near the city center receive more media attention than those on the outskirts (Lindgren, 2009, p. 88; Oliver \& Myers, 1999, p. 64). Moreover, neighborhoods with large shares of marginalized populations often garner attention, but it tends to be stereotypical, focused on crime and policing, and often does not cover relevant issues such as municipal politics or education (Lindgren, 2009, p. 91; Wiard \& Pereira, 2019, p. 662). 
These findings suggest that socially constructed spaces are embedded within the content of public communication. These do not merely mirror relatively neutral factors, such as landmass or population size, but carry ideas of how newsworthy events in different places are, and thereby spatially allocate public attention. This emphasizes the necessity of integrating the spatiality of content in the study of public discourses.

Still, these strands of research only allow limited conclusions about digital public discourses. First, as journalistic news media cover a broad range of issues, news geography research usually does not account for how different issues are spatialized, but instead studies media's "representational space" (Gasher \& Klein, 2008, p. 196) at large. This is not well-suited for capturing online discourses, which are structured around specific issues. Second, news media attention is allocated by a comparatively small set of professional journalistic actors. The spatiality of news content will, therefore, be driven by news production routines (e.g., where a medium's headquarters are located or where it has foreign correspondents). By comparison, the allocation of attention in the digital public, especially on social media, is driven by a more heterogeneous actor set including local politicians, small civil society organizations, and private individuals. If local actors become more empowered to speak for themselves, it may cause a shift in the differentials between centers and peripheries, or proximate and distant places. Third, this may also bring in a greater heterogeneity in how places are talked about. On the one hand, spatial references may be used less formalistically. While in journalism, places are often demarcated by a dateline, they may be embedded in less predictable ways in digital communication. On the other hand, the spatial references themselves may differ. Smaller spatial units (e.g., individual addresses) or informal place-names (e.g., neighborhoods, which are recognized by residents, but not administratively designated) may become more visible.

All of these aspects call for a new and more explicit perspective for researching the spaces of public communication. Issue spatiality offers such a framework.

\section{Issue Spatiality: A Conceptual Framework}

The central proposition of this article is that spatiality should be understood as a dimension of any public issue. That is, public issues always carry a spatial dimension, which is constructed when interlocutors in the discourse address the question of 'where.' The idea of spaces as discursively constructed was highlighted by Richardson and Jensen in their proposition for a spatial policy discourse analysis: "Spaces and places do not present themselves, but are rather represented by means of power relations expressed in strategies, discourses, and institutional settings" (Richardson \& Jensen, 2003, p. 18). Both issues (Miller \& Riechert, 2001, p. 106) and spaces (Löw, 2008, p. 38) are understood as socially constructed through public communication.
The concepts of space and place deserve some further attention. My understanding of these categories is primarily informed by the notion of relational space put forward by Martina Löw. Following her sociology of space, "spaces do not simply exist but are created in (generally repetitive) action, and... as spatial structures embedded in institutions, they guide action" (Löw, 2008, p. 40). This means that space does not exist as an independent 'container' in which social processes take place, but it emerges from the act of perceiving objects in relation to each other (Löw, 2008, p. 35). Such an emphasis on the socially produced nature of space builds on earlier work by critical scholars like Henri Lefebvre (1991) and Edward Soja (1989). In Löw's (2008) understanding, two processes are important for the constitution of space: objects and goods are (1) positioned (spacing), and (2) perceived as relating to each other (synthesis). I understand synthesis as a social and communicative process (Knoblauch \& Steets, 2020, pp. 140-141), with public communication playing a central role.

Place may be understood as a specific form of space. For Löw, 'localization' is critical for the constitution of space. Localization describes instances where spaces become anchored to localities on the earth's surface and thereby become places. Place, therefore, "denotes an area, a site, which can be specifically named, usually geographically marked....Naming intensifies the symbolic impact of places" (Löw, 2008, p. 42). Beyond being mere geographic markers, place-names are collectively recognized by communities and stakeholders and often carry ideas and ideologies about the character of particular localities (Gutsche, 2014, p. 504). Place-names, be it the names of countries, cities, or streets, are intersubjectively recognizable. Their use, therefore, enables a shared understanding of location.

I propose 'place-naming' (Gutsche, 2014; Wiard \& Pereira, 2019) as the central practice in the formation of issue spatiality. That is, issue spatiality emerges through the localization of issues when public communication associates place-names and issues. We may imagine two intertwined processes: First, issues become associated with 'places'; second, through their discursive connection to the same issue, these places are synthesized as relating to each other and belonging to the same issue 'space.'

Issue spatiality should therefore be understood as a macro-level property of public issue discourses. No individual piece of communication, be it a news article, a statement by a politician, or a tweet, creates an issue space. Instead, it is the repeated invocation of places in conjunction with issues by a diverse set of actors that spatializes public issues. I differentiate between 'issue spatiality' (the analytical framework which focuses on the spatial dimension of issues) and 'issue space' (the spatial shape of any particular, empirically observable issue discourse). So, while issue spatiality provides the theoretical lens for investigating the spatial dimension of any issue discourse, such an analysis makes visible a specific issue space. This may be, for example, the totality of 
places associated with climate change, globally, or with the issue of affordable housing within a particular city.

\subsection{The Question of Scale}

Actors may publicly refer to cities, countries, continents, addresses, or streets. They are also not confined to administratively designated territories (Wiard \& Pereira, 2019 , p. 656). Instead, if a place-name is meaningful to the relevant public, nicknames or informal areas can equally shape issue spaces. Consequently, issue spatiality is not fixed to any particular scale, and which scales are most pertinent may shift depending on the focus of the debate.

Some issues may still be more closely associated with some scales than others. For instance, climate changeoften understood as a global issue, even though it impacts different places in different ways-may be more naturally understood by focusing on a global scale and expecting place-naming to occur at the level of countries or regions. In contrast, a discourse around housing markets can be expected to be more closely tied to an individual metropolitan region, both due to political competencies and the constraints facing individual actors. That is, if people are priced out of one neighborhood, they may look for housing elsewhere in the city, but will not typically move somewhere else entirely. One may expect the issue space for such a debate to be focused on smallerscale units, such as neighborhoods or even streets.

While this suggests that some scales will be more pertinent for particular issues, this relation is not determinative. Housing, for instance, may become spatialized at higher scales if a national debate makes comparisons with other cities relevant, or if transnational NGOs draw connections with the issue in other countries. Or climate change may be downscaled if local weather events are communicatively connected to it, or if activists link environmental protection in one town to climate protection broadly.

\subsection{Dimensions of Issue Spatiality}

The types of messages which shape issue spatiality are not monolithic. In digital public spheres, a multitude of actors, each with their own perspectives, interests, and positionalities, contribute to the formation of discourse (Waldherr, 2017, pp. 540-541). Issue spatiality is therefore shaped by both actors located in place (residents) and those located elsewhere (non-residents). While local communities use digital media to generate visibility for themselves, this does not remove outside voices from the equation. Media, political actors, or simply individuals who reside elsewhere will routinely engage in communication about places. Without selfdisclosure by speakers, it will often be impossible for the audience to separate contributions by residents and non-residents. Moreover, there are intermediate forms if, for instance, residents share media coverage about their places on social media. Issue spatiality should therefore be understood as an amalgam of resident and non-resident communication.

Driven by this actor diversity, a diversity of message types can be expected. This includes messages which report events which occur in a place (e.g., a protest, a flood) or events which occur elsewhere but affect a place (e.g., a political decision). Moreover, messages may not merely inform about events in places, but express opinions about them, thereby creating places of action or inaction, hope or despair, desirable or undesirable outcomes. Furthermore, in line with Marwick and boyd's (2011) notion of context collapse, there are messages, which are not (exclusively) directed at a broad public, but address specific stakeholders (e.g., political actors), while also being publicly visible and searchable on the web. These may even include messages about primarily private concerns, which-by virtue of their visibility-can still shape public understanding of issues.

While this list of possible contexts of place-naming is not exhaustive, it illustrates that, in digital discourses, issue spatiality is the product of multiple, entangled types of communication. Consequently, there are several dimensions of issue spatiality.

\subsubsection{Overall Distribution of Place-Naming Prevalence}

At a basic level, issue spatiality is shaped by the distribution of how frequently different places are named within public communication about an issue. This is relatively close to the concept of news geography (Gasher \& Klein, 2008), albeit applied to a specific issue, instead of public attention overall. This dimension simply asks how frequently different locations are invoked within a given issue discourse. How frequently, for instance, are different neighborhoods discussed in the discourse around housing in a city? Or how frequently are different countries or regions associated with climate change? And, on a more aggregate level, what is the attention allocation between, for instance, the city center and the outskirts, urban and rural areas, or the Global North and the Global South?

The answer to these questions about the overall (lack of) visibility for specific places can already shape public imagination of where an issue is relevant. Still, issue publics tend to cover relatively broad subject areas with several sub-issues, frames (Maier et al., 2017, pp. 6-7), and conflicting perspectives (Miller \& Riechert, 2001, p. 108). Place-naming may occur in messages which emphasize or deny a problem or make relevant only a specific sub-issue. Therefore, only accounting for the overall place-naming distribution is under-complex.

\subsubsection{Distribution of Place-Based Sub-Issues or Issue Narratives}

Digital issue publics are shaped by the confluence of different sub-issues and conflicting perspectives. Moreover, 
they include a heterogeneous set of contributions, with a focus on narratives and personal stories, sometimes tied together into activist frames (Bennett \& Segerberg, 2012, p. 2). Understanding the conjunction between message content and place-naming is therefore critical for grasping issue spatiality.

It is plausible that different sub-issues and narratives will be spatialized differently, depending on the local properties of social problems, the local actors organizing around them, or other actors' preconceived notions about places (see Lindgren, 2009, p. 88). In the climate change example, this may mean that the issue space for pollution is different from the one for wildfires. Or, in the case of housing, some neighborhoods may be associated primarily with gentrification, others with construction, and others may be discussed as still being affordable places to live. We may also see some places framed primarily as the locus of problems (Wiard \& Pereira, 2019, p. 662-664), while others are discussed with a more positive valence. Moreover, some places may become much more associated with activist narratives, while others may become visible mostly through journalistic coverage.

\subsubsection{Spatial Integration}

Public discourses, in general, can also be understood as ranging between fragmented and integrated. While most frequently, these categories are used to describe the extent to which different ideological positions come into contact (e.g., Dahlberg, 2007), it is useful to also think of integration spatially. Following the notion that-rather than a unitary public sphere-we are increasingly seeing a multitude of smaller (counter-)publics (Fraser, 1990), we can imagine local settings as small publics. Resident discourse in individual neighborhoods in response to local changes in the housing markets, for instance, may be thought of as such a small, grassroots public, as might local organizing against deforestation as a climate threat. Many of these local publics may contribute to an issue space, and each public may consist of different actors (both residents and non-residents) voicing separate concerns.

However, to have an impact, publics need to be at least partially integrated into larger discourses (Fraser, 1990 , p. 68). Spatial integration is therefore an important dimension of issue spatiality. We can investigate this by focusing on the interconnectedness of local debates (Kleinen-von Königslöw, 2010, p. 41), that is, the extent to which different arenas share speakers. For issue spatiality, research should ask to what extent the same actors discuss different places. Since much attention in digital spheres is allocated via routinized 'following' behavior, actors who discuss multiple places present them as related to the same audience. If the same actoror, more importantly, still-the same message problematizes the impact of climate change in Brazil and the Netherlands, the two are related as belonging to the same issue space. If these localized discourses remain atomized, however, the issue space itself is fragmented.

\subsubsection{Distribution of Resonance}

Reactions to public communication play a critical role in digital public spheres, in particular. The degree to which others interact with messages by liking, sharing, or commenting on them increases their reach. This resonance, however, is extremely unequally distributed (Shirky, 2005). The spatial distribution of resonance, therefore, constitutes its own dimension of issue spatiality. It is conceivable that some places are talked about, without such messages receiving broader attention. This would limit their influence on the public perception of an issue space. On the flipside, even infrequent place references may have an outsized influence if they generate a great deal of resonance.

It is not clear whether the patterns of place-naming overall will resemble these distributions of resonance and amplification. One may be more unequal than the other or they may deviate in other ways. For example, if discussions of gentrification and housing shortages in one neighborhood are amplified more than similar discussions about another neighborhood, the former will become more closely associated with the issue, even if both were the subject of the same number of original messages in the beginning.

Altogether, there are several distinct dimensions of issue spatiality. These not only capture different aspects of the spatiality of public issues, but there may even be contradictions in their empirical expression. For example, a place may receive a great deal of attention, but most of it may deny that an issue is pertinent there. Or a large number of actors may discuss a local issue, without generating resonance. Understanding the qualitative interplay between the dimensions is therefore a critical challenge.

\subsection{Predictors of Issue Spatiality}

In line with results from news geography research and research on the allocation of attention in digital contexts broadly, we should expect issue spatiality to be characterized by an extremely unequal attention distribution, with some places becoming highly associated with an issue, while others remain invisible. The relation between places, events, and their public image is likely influenced by a number of "selective and distorting factors" (Galtung \& Ruge, 1965, p. 64). The question of which properties can predict the shape of an issue space then presents itself. News values research has generated considerable knowledge of the properties which increase the likelihood that events become news. These news factors will not be rehashed here (for an overview, see Ruhrmann et al., 2003, pp. 53-59).

Yet, shifting the focus from events to places, and from exclusively journalistic coverage to the broader actor set 
of digital public spheres can enhance researchers' perspectives. Such a shift draws attention to the question of what local properties, specific to places, may predict public attention.

If actors more frequently speak for themselves and the issues of their local environment, questions of sociospatial inequalities in communicative infrastructures and resources are pertinent. At the local level, communication is fostered or constrained by physical, psychological, sociocultural, economic, and technological factors. This may include the availability of community meeting places, time, and resources to engage in public communication, or the social composition of communities (Ball-Rokeach et al., 2001, pp. 396-397). Especially for global issues spaces, accounting for digital divides (e.g., Chen \& Wellman, 2004) will be critical.

As professional communicators, such as media, NGOs, or politicians, continue to play an important role in public communication, their habits and logics also need to be considered. The availability and quality of local organizations can connect inhabitants and enable them to become publicly engaged. Moreover, these organizations may become communicators themselves (Ball-Rokeach et al., 2001, p. 397) and thereby enhance local visibility. Professional actors may also have spatial habits. For example, media and political actors may preferentially focus on urban centers, which tend to be closer to their workplaces (Oliver \& Myers, 1999, p. 64), or media may be more likely to cover places where they have correspondents. In this way, location centrality may become its own factor in explaining issue spatiality.

The local properties of social problems should also be considered. Especially, "events that heighten salience and manifest an area as having its own identity (e.g., a shared threat or opportunity)" (Ball-Rokeach et al., 2001, p. 394) can trigger public communication. For a local housing discourse, this may mean accounting for the increase in rental costs. For a climate change discourse, it may be necessary to consider whether places have experienced extreme weather events. Accounting for such data can also aid in understanding the extent to which issue spatiality is actually driven by issues versus other socio-spatial properties of places.

\section{Towards the Empirical Study of Issue Spatiality}

I have argued that not considering the spatial dimension created through the content of issue discourses constitutes an omission in the study of issue publics, and laid out a conceptual framework for addressing this gap. The question remains, then, of how issue spatiality can be leveraged for empirical research. The dearth of attention for questions of space in public communication is mirrored in a sparsity in the use of geospatial data in communication research. Connecting these data and their analysis with more established methods of social-scientific empirical research is the central demand for studying issue spatiality. Within the field of public spheres research, this especially means integrating geospatial data into content analytical approaches. In particular, place-naming needs to be operationalized and geographic data visualization techniques need to be incorporated into analyses. To fully grasp the complexity of issue spaces, analyses should include quantitative, qualitative, as well as large-scale computational approaches.

The first concrete challenge in operationalizing issue spatiality is the measurement of place-naming. That is, how can one capture spatial references in a valid, reliable, and scalable fashion? The few studies which have investigated this type of question have relied on manual content analysis, with human coders reading texts and identifying geographic references (Lindgren, 2009, pp. 81-83; Wiard \& Pereira, 2019, p. 660). Such an approach is valid and reliable, but limits the feasible size of the document corpus and, as spatial references tend to be sparse, is relatively inefficient. For small text collections, this remains a good approach, as human coders with context knowledge will be able to detect unexpected place references, misspellings, or nicknames. It may be seen as the gold standard in location detection (Takhteyev et al., 2012, p. 76).

For larger text collections, the use of gazetteers (geographical dictionaries), which has a tradition in neighboring disciplines, may be fruitfully adapted by communication studies. For some applications, there are tools available. In the area of computational methods, Named Entity Recognition (NER) tools are often capable of detecting units such as countries, cities, or states (e.g., Honnibal \& Montani, n.d.). More specific purposes, such as the detection of every street within a city, will require researchers to construct their own gazetteers. The challenges, then, lie in determining which spatial references are of interest and creating comprehensive, valid, and unambiguous dictionaries. But once completed, such an approach is highly scalable and perfectly reliable. Thanks to the increasing availability and accessibility of computational methods toolkits, such as quanteda (Benoit et al., 2018), the application of these geographical dictionaries even to very large text collections has become relatively straightforward. Yet, the use of gazetteers is not without drawbacks. If research requires the inclusion of non-administrative spatial units, such as neighborhoods, the effort required in creating comprehensive gazetteers is high. Moreover, as place-names often exist more than once in the world, ambiguity is an important problem. Besides the effort of creating gazetteers, systematic validation is therefore necessary. Whether the use of manual coding or an automated approach is more appropriate must be decided primarily based on data volume and the degree of prior knowledge about what place-names may be relevant in the discourse.

Second, having detected instances of place-naming, communication scholars will have to strive for the integration of mapping techniques into their methodological toolkit to better understand the emerging spatial 
patterns related to different issues. As Lindgren and Wong (2012) explain, maps can be leveraged by communication scholars for exploring the construction of spatial knowledge. This requires acquainting oneself with methods for creating maps, either via special Geographic Information System (GIS) software or libraries geared towards geographic visualization in $\mathrm{R}$ or Python. Here, too, recent advances in computational social science approaches enhance the possibilities for studying issue spatiality. Yet, these tools require specialized methodological training, which is not currently part of the standard curriculum for communication scholars.

The detection of place-naming and spatial data visualization techniques are two necessary steps for using geospatial data in public spheres research. Integrating both, researchers can grasp the overall distribution of place-naming prevalence. Third, for understanding the other dimensions of issue spatiality, combining geospatial data and their analysis with more traditional methods of empirical social research will be critical. Content analysis can be connected to gazetteers and mapping approaches to understand how different sub-issues and narratives are spatialized. This may include quantitative coding, as carried out by Lindgren (2009) or Wiard and Pereira (2019). For larger text corpora, or if not enough is known about the discourse to deductively derive categories, inductive computational approaches such as topic modelling (Maier et al., 2018) are promising, especially in combination with more qualitative steps (Nelson, 2017). Bringing these approaches together will allow not only the mapping of overall attention distribution in space but will also enable researchers to see how different sub-issues are spatialized.

Spatial integration of a discourse can be understood as semantic co-occurrence of place names in the communication of the same actors. Here, semantic network analysis (e.g., Xiong et al., 2019), which connects places whenever they are referenced by the same actor or in the same message, is a promising avenue. Understanding the distribution of resonance means accounting for engagement markers (likes, shares) and mapping their distribution for different spatial references.

Taken together, these considerations highlight that, in principle, geospatial data can be combined with any method currently employed in the analysis of public discourses. By doing so, it is possible to add the question of spatiality as a new layer to the empirical analysis of public issue discourses.

\section{Conclusions}

I have introduced issue spatiality as a conceptual framework for investigating the spaces embedded in the content of public communication. Issue spatiality was defined as emerging through the localization of issues when acts of public communication associate placenames and issues. There are different dimensions to it, extending beyond the overall distribution of place- naming to include the spatiality of different sub-issues and narratives, the spatial integration of local discourses, and the distribution of resonance. The socio-spatial distribution of communicative resources and infrastructures, professional communicators and their spatial behavior, as well as local problem properties, were identified as likely predictors for the shape of issue spaces. For future empirical inquiries, the integration of gazetteers as well as mapping techniques into communication research were discussed as methodological interventions.

The primary goal of introducing issue spatiality was to enable a more focused and explicit understanding of how space is discursively constructed as a dimension of public issues. In line with broader conceptions of public spheres, this not only includes the allocation of attention but also enables a more nuanced look at the way issues and narratives become tied to places and the way some places may be more connected to broader issue discourses than others. Conceptualized like this, issue spatiality has clear precedents in the study of public communication, but it extends and shifts their focus. It shares the interest in the spatial allocation of visibility with news geography and news values research. Yet, by centering the connection between issues and space, it more clearly brings into view the differences and commonalities between different public discourses. It also has these concerns in common with the research of transnational or European public spheres, but unlike these concepts, it is not tied to any particular scale or narrowly focused on processes of border-crossing in public discourses. Finally, compared to the way space is currently conceptualized in much of communication research, it highlights the socially constructed nature of space, instead of treating it as a mere backdrop against which events take place.

The framework thus enables researchers to empirically address the research desideratum of how issue spaces are discursively constructed, especially in digital public spheres. Future research within this area has several tasks. It must study the degree to which the spaces of different issues vary. This will facilitate an understanding of the extent to which issue spatiality is specific to the nature of the issue versus driven by more universal underlying socio-spatial patterns. This also necessitates investigating the influence of different predictors on issue spatiality. Moreover, public spheres research needs to better grasp how issues of different scales are spatialized. To what extent, for instance, are translocal connections formed, even within local issue discourses? And how are global issues made specific through the attachment to localities? Finally, to comprehensively grasp the spatiality of public spheres, empirical research should study the connections between actor spatiality, network spatiality, and issue spatiality.

\section{Acknowledgments}

The research is funded by the DFG (Deutsche Forschungsgemeinschaft / German Research Foundation)-project 
number 290045248-SFB 1265. I would like to thank Hatem Hegab for his help during the revision of this manuscript and the three anonymous reviewers for their thoughtful and constructive feedback.

\section{Conflict of Interests}

The author declares no conflict of interests.

\section{References}

Ball-Rokeach, S. J., Kim, Y.-C., \& Matei, S. (2001). Storytelling neighborhood: Paths to belonging in diverse urban environments. Communication Research, 28(4), 392-428. https://doi.org/10.1177/ 009365001028004003

Benkler, Y. (2006). The wealth of networks: How social production transforms markets and freedoms. Yale University Press.

Bennett, W. L., Lang, S., \& Segerberg, A. (2015). European issue publics online: The cases of climate change and fair trade. In T. Risse (Ed.), European public spheres: Politics is back (pp. 108-137). Cambridge University Press.

Bennett, W. L., \& Segerberg, A. (2012). The logic of connective action: Digital media and the personalization of contentious politics. Cambridge University Press.

Benoit, K., Watanabe, K., Wang, H., Nulty, P., Obeng, A., Müller, S., \& Matsuo, A. (2018). quanteda: An R package for the quantitative analysis of textual data. Journal of Open Source Software, 30(3), 774. https://doi. org/10.21105/joss.00774

Castells, M. (2008). The new public sphere: Global civil society, communication networks, and global governance. The ANNALS of the American Academy of Political and Social Science, 616(1), 78-93. https:// doi.org/10.1177/0002716207311877

Chen, W., \& Wellman, B. (2004). The global digital divide: Within and between countries. IT \& Society, 1(7), 39-45.

Dahlberg, L. (2007). Rethinking the fragmentation of the cyberpublic: From consensus to contestation. New Media \& Society, 9(5), 827-847. https://doi.org/ $10.1177 / 1461444807081228$

Fraser, N. (1990). Rethinking the public sphere: A contribution to the critique of actually existing democracy. Social Text, 25/26(1990), 56-80. https://doi.org/ $10.2307 / 466240$

Fraser, N. (2007). Transnational public sphere: On the legitimacy and efficacy of public opinion in a postWestphalian world. Theory, Culture \& Society, 24(4), 7-30. https://doi.org/10.1177/0263276407080090

Galtung, J., \& Ruge, M. H. (1965). The structure of foreign news: The presentation of the Congo, Cuba and Cyprus crises in four Norwegian newspapers. Journal of Peace Research, 2(1), 64-90. https://doi.org/ 10.1177/002234336500200104

Gasher, M., \& Klein, R. (2008). Mapping the geogra- phy of online news. Canadian Journal of Communication, 33(2), 193-212. https://doi.org/10.22230/cjc. 2008v33n2a1974

Gerhards, J., \& Neidhardt, F. (1991). Strukturen und Funktionen moderner Öffentlichkeit: Fragestellungen und Ansätze [Structures and functions of the modern public sphere: Research questions and approaches]. In S. Müller-Doohm \& K. NeumannBraun (Eds.), Studien zur Soziologie und Politikwissenschaft. Öffentlichkeit, Kultur, Massenkommunikation: Beiträge zur Medien-und Kommunikationssoziologie [Studies in sociology and political science: Public sphere, culture, mass communicationContributions to media and communication sociology] (pp. 31-89). Bis.

Gutsche, R. E. (2014). News place-making: Applying 'mental mapping' to explore the journalistic interpretive community. Visual Communication, 13(4), 487-510. https://doi.org/10.1177/147035721 4541754

Habermas, J. (1992). The structural transformation of the public sphere. Polity Press.

Habermas, J. (1996). Between facts and norms. Polity Press.

Hess, K. (2013). Breaking boundaries: Recasting the "local" newspaper as "geo-social" in a digital landscape. Digital Journalism, 1(1), 48-63. https://doi. org/10.1080/21670811.2012.714933

Honnibal, M., \& Montani, I. (n.d.). spaCy 3: IndustrialStrength Natural Language Processing. https://spacy. io

Jangdal, L. (2021). Hyperlocals matter: Prioritising politics when others don't. Journalism Practice, 15(4), 438-455. https://doi.org/10.1080/17512786. 2020.1739551

Kleinen-von Königslöw, K. (2010). Die Arenen-Integration nationaler Öffentlichkeiten. Der Fall der wiedervereinten deutschen Öffentlichkeit [The arena integration of national public spheres: The case of the re-unified German public sphere]. Springer.

Knoblauch, H., \& Steets, S. (2020). Von der Konstitution zur kommunikativen Konstruktion des Raums [From the constitution to the communicative construction of space]. In J. Reichertz (Ed.), Grenzen der Kommunikation-Kommunikation an den Grenzen [Boundaries of communication: Communication at boundaries] (pp. 134-148). Velbrück Wissenschaft.

Kwak, H., \& An, J. (2014). A first look at global news coverage of disasters by using the GDELT dataset. In L. M. Aiello \& D. McFarland (Eds.), Proceedings of social informatics: 6th international conference, SocInfo 2014 (pp. 300-308). Springer. https://doi. org/10.1007/978-3-319-13734-6_22

Leetaru, K., Wang, S., Padmanabhan, A., \& Shook, E. (2013). Mapping the global Twitter heartbeat: The geography of Twitter. First Monday, 18(5). https:// doi.org/10.5210/fm.v18i5.4366

Lefebvre, H. (1991). The production of space. Blackwell. 
Lindgren, A. (2009). News, geography and disadvantage: Mapping newspaper coverage of high-needs neighbourhoods in Toronto, Canada. Canadian Journal of Urban Research, 18(1), 74-97.

Lindgren, A., \& Wong, C. (2012). Want to understand local news? Make a map (Journalism Publications and Research Paper 3). Ryerson University. https://digital.library.ryerson.ca/islandora/object/ RULA\%3A285/datastream/OBJ/view

Lingenberg, S. (2014). Mobilisiert-mediatisierte Lebenswelten und der Wandel des öffentlichen Raums [Mobilized-mediated life worlds and the transformation of public space]. In J. Wimmer \& M. Hartmann (Eds.), Medienkommunikation in Bewegung: Mobilisierung-Mobile Medien-Kommunikative Mobilität [Media communication in motion: Mobilization-Mobile media-Communicative mobility] (pp. 69-86). Springer.

Löw, M. (2008). The constitution of space: The structuration of spaces through the simultaneity of effect and perception. European Journal of Social Theory, 11(1), 25-49. https://doi.org/10.1177/1368431007085286

Maier, D., Waldherr, A., Miltner, P., Jähnichen, P., \& Pfetsch, B. (2017). Exploring issues in a networked public sphere: Combining hyperlink network analysis and topic modeling. Social Science Computer Review, 36(1), 3-20. https://doi.org/10.1177/ 0894439317690337

Maier, D., Waldherr, A., Miltner, P., Wiedemann, G., Niekler, A., Keinert, A., Pfetsch, B., Heyer, G., Reber, U., Häussler, T., Schmid-Petri, H., \& Adam, S. (2018). Applying LDA topic modeling in communication research: Toward a valid and reliable methodology. Communication Methods and Measures, 12(2/3), 93-118. https://doi.org/10.1080/ 19312458.2018.1430754

Marwick, A. E., \& boyd, d. (2011). I tweet honestly, I tweet passionately: Twitter users, context collapse, and the imagined audience. New Media \& Society, 13(1), 114-133. https://doi.org/10.1177/ 1461444810365313

Miller, M. M., \& Riechert, B. P. (2001). The spiral of opportunity and frame resonance: Mapping the issue cycle in news and public discourse. In S. D. Reese, O. H. Gandy Jr., \& A. E. Grant (Eds.), Framing public life: Perspectives on media and our understanding of the social world (pp. 106-121). Lawrence Erlbaum Associates.

Nelson, L. K. (2017). Computational grounded theory: A methodological framework. Sociological Methods \& Research, 49(1), 3-42. https://doi.org/10.1177/ 0049124117729703

Oliver, P. E., \& Myers, D. J. (1999). How events enter the public sphere: Conflict, location, and sponsorship in local newspaper coverage of public events. American Journal of Sociology, 105(1), 38-87. https://doi.org/ $10.1086 / 210267$

Pfetsch, B., Maier, D., Stoltenberg, D., Waldherr, A.,
Kligler-Vilenchik, N., \& de Vries Kedem, M. (2019, May 24-28). How local is the digital public sphere on Twitter? A comparison between Jerusalem and Berlin [Paper presentation]. 69th Annual Conference of the International Communication Association, Washington, DC, USA.

Richardson, T., \& Jensen, O. B. (2003). Linking discourse and space: Towards a cultural sociology of space in analysing spatial policy discourses. Urban Studies, 40(1), 7-22. https://doi.org/10.1080/ 00420980220080131

Risse, T. (Ed.). (2015). European public spheres: Politics is back. Cambridge University Press.

Ruhrmann, G., Woelke, J., Maier, M., \& Diehlmann, N. (2003). Der Wert von Nachrichten im deutschen Fernsehen. Ein Modell zur Validierung von Nachrichtenfaktoren [The value of news on German television: A model for the validation of news factors]. VS Verlag für Sozialwissenschaften. https://doi.org/ 10.1007/978-3-663-09644-3

Schäfer, M. (2016). Digital public sphere. In G. Mazzoleni (Ed.), The international encyclopedia of political communication. https://doi.org/10.1002/ 9781118541555.wbiepc087

Shirky, C. (2005). Power laws, weblogs and inequality. In J. Lebkowsky \& M. Ratcliffe (Eds.), Extreme democracy (pp. 46-52). Lulu Press.

Soja, E. (1989). Postmodern geographies: The reassertion of space in critical social theory. Verso.

Takhteyev, Y., Gruzd, A., \& Wellman, B. (2012). Geography of Twitter networks. Social Networks, 34(1), 73-81. https://doi.org/10.1016/j.socnet.2011. 05.006

Volkmer, I. (2014). The global public sphere: Public communication in the age of reflective interdependence. Polity Press.

Waldherr, A. (2017). Öffentlichkeit als komplexes System: Theoretischer Entwurf und methodische Konsequenzen [The public sphere as a complex system: Theoretical framework and methodological consequences]. Medien \& Kommunikationswissenschaft, 65(3), 534-549. https://doi.org/10.5771/1615634X-2017-3-534

Wallner, C., \& Adolf, M. (2014). Räume und Kontexte öffentlicher Kommunikation [Spaces and contexts of public communication]. In J. Wimmer \& M. Hartmann (Eds.), Medienkommunikation in Bewegung: Mobilisierung-Mobile Medien-Kommunikative Mobilität [Media communication in motion: Mobilization-Mobile media-Communicative mobility] (pp. 87-101). Springer. https://doi.org/10.1007/ 978-3-531-19375-5_5

Wehden, L.-O., \& Stoltenberg, D. (2019). So far, yet so close: Examining translocal Twitter audiences of regional newspapers in Germany. Journalism Studies, 20(10), 1400-1420. https://doi.org/10.1080/ 1461670X.2018.1520609

Wiard, V., \& Pereira, F. H. (2019). Bad neighborhoods in 
a good city? Space, place and Brussels' online news. Journalism Studies, 20(5), 649-674. https://doi.org/ 10.1080/1461670X.2017.1417052

Wilke, J., Heimprecht, C., \& Cohen, A. (2012). The geography of foreign news on television: A comparative study of 17 countries. International Communication Gazette, 74(4), 301-322. https://doi.org/
$10.1177 / 1748048512439812$

Xiong, Y., Cho, M., \& Boatwright, B. (2019). Hashtag activism and message frames among social movement organizations: Semantic network analysis and thematic analysis of Twitter during the \#MeToo movement. Public Relations Review, 45(1), 10-23. https://doi.org/10.1016/j.pubrev.2018.10.014

\section{About the Author}

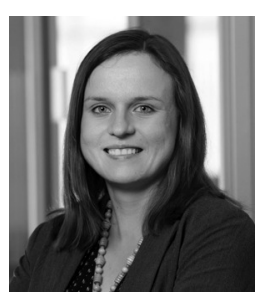

Daniela Stoltenberg (MA) is a Research Associate and PhD Candidate at Freie Universität Berlin. She currently works in the research project "Translocal Networks: Public Spheres in the Social Web," which is part of the Collaborative Research Center 1265 "Re-Figuration of Spaces." Her research focuses on public spheres theory, digital communication in cities, and the intersection between communication and space. She is also interested in combining computational social science approaches with more traditional quantitative and qualitative research methods. 